\title{
Respiratory impairment in persons with multiple sclerosis: A cross-sectional study
}

\author{
Guillermo J. Ruiz-Delgado ${ }^{1,2,3 *}$, Danitza Fernández-Lara1 , Iván Murrieta-Álvarez ${ }^{1,3}$, Gisela B. Gómez-Cruz ${ }^{4}$, \\ Jesús M. Olivares-Gazca', ${ }^{1,3}$, Juan C. Olivares-Gazca ${ }^{1,3}$, Andrés A. León-Peña ${ }^{1,4}$, Yahveth Cantero-Fortiz ${ }^{1,5}$, \\ Sofía Banck-Angulo ${ }^{5}$, Kassandra Pérez-Turrent ${ }^{5}$, Griselda Fuentes-Fuentes ${ }^{1,6}$, and \\ Guillermo J. Ruiz-Argüelles ${ }^{1,2,3}$
}

${ }^{1}$ Departamento de Investigación, Centro de Hematología y Medicina Interna de Puebla, Clínica Ruiz; ${ }^{2}$ Departamento de Hematología, Laboratorios Clínicos de Puebla; ${ }^{3}$ Facultad de Medicina, Universidad Popular Autónoma del Estado de Puebla; ${ }^{4}$ Facultad de Medicina, Benemérita Universidad Autónoma de Puebla; ${ }^{5}$ Escuela de Medicina, Universidad de las Américas Puebla; ${ }^{6}$ Departamento de Neurología, Hospital Regional de Zona. Puebla, Mexico

\begin{abstract}
Introduction: The spectrum of multiple sclerosis (MS) among all its clinical types includes a vast number of alterations. Of these, respiratory impairment carries big implications since this is an important cause of mortality and morbidity. Methods: Here, we present an observational study of respiratory assessment through spirometry in individuals with MS. Subjects who underwent autologous hematopoietic stem cell transplant from an interventional study were considered to participate. Results: An abnormal pattern of respiratory impairment was found in 147 participants; of this, $89.6 \%$ and $10.4 \%$ manifested a restrictive and obstructive pattern, respectively. The restrictive pattern was observed in 58 patients with secondary-progressive MS (SPMS) followed by 36 in patients with relapsing-remitting MS (RRMS) and, finally, 37 in patients with primary-progressive MS (PPMS). The full population had a mean forced expiratory volume of the $1^{\text {st }} S$ (FEV1) of $92 \%$, while the RRMS, PPMS, and SPMS groups had 93\%, 89\%, 91\%, respectively. The median FEV1/forced vital capacity (FVC) ratio was $82.8 \%$ in the full cohort, $83.3 \%$ in the RRMS group, $83 \%$ in the PPMS group, and $82 \%$ in the SPMS group. Negative correlations were found between predicted FVC and FEV1 with expanded disability status scale and FEV1/FVC. Conclusion: This study showed a considerable number of restrictive patterns among all the participants, being the SPMS the type of MS with higher respiratory involvement and with functional disability.
\end{abstract}

Key words: Multiple sclerosis. Spirometry. Respiratory impairment.

\section{Introduction}

Multiple sclerosis (MS) is a chronic, inflammatory, and autoimmune disorder characterized by the destruction of the central nervous system (CNS) myelin with varying degrees of axonal damage that affects nerve conduction ${ }^{1-4}$. This disease has a diverse and unpredictable course, leading to episodes of neurological deficits followed by progressive neurological deterioration; its symptoms may include cognitive impairment, impairment of coordination, spasticity, muscle weakness, vision loss, and generalized fatigue. The clinical presentation of these symptoms may be relapsing, remitting, or progressive ${ }^{1,2}$. MS usually affects young adults, being more frequent in women than in men with a ratio of $2: 1^{1,4}$.

\section{Correspondence:}

*Guillermo J. Ruiz-Delgado

E-mail: gruiz2@ clinicaruiz.com
Available online: 09-12-2019

Date of reception: 20-06-2019

Date of acceptance: 29-08-2019 DOI: 10.24875/RMU. 19000101
Medicina Universitaria. 2019;21(4):157-163 www.medicinauniversitaria.org

665-5796/@ 2019 Universidad Autónoma de Nuevo León. Published by Permanyer. This is an open access article under the CC BY-NC-ND license (http://creativecommons.org/licenses/by-nc-nd/4.0/). 
MS patients develop severe lung complications. Many may experience a reduced pulmonary respiratory inspiratory and expiratory muscle strength and/or diffusion capacity, leading to an impaired pulmonary function, even at the onset of MS. Such deterioration in pulmonary function may lead to ineffective cough, retention of secretions and inability to maintain clear airways, increasing the risk for the development of atelectasis and pneumonia.

\section{Methods}

\section{Design}

This is a cross-sectional observational study, derived from the population of the prospective, the interventional study "Outpatient Hematopoietic Grafting in MS Employing Autologous Peripheral Blood Stem Cells" (ClinicalTrials.gov identifier NCT02674217) ${ }^{4}$. The aim of the study was to assess and correlate the respiratory function and physical disability among individuals with MS who underwent hematopoietic stem cell transplantation (HSCT). As part of the HSCT protocol in our institution, all patients are assessed with pulmonary function tests (PFTs) as a baseline reference of the pulmonary function, since approximately $25 \%$ of the patients develop pulmonary complications within the $1^{\text {st }}$ year of autologous $\mathrm{HSCT}^{5}$. Clínica Ruiz Institutional Review Board approved this study, and every participant signed and provided a consent document before the study.

\section{Subjects}

All patients who underwent treatment from July 2015 to November 2018 were included in the analysis. The inclusion criteria for the interventional study were as follows:

- Patients having relapsing-remitting, secondary progressive, and PPMS

- Karnofsky performance status of at least $70 \%$ and expanded disability status scale (EDSS) of 8 or below

- Not been treated with immune suppressant drugs 3 months before the study.

While the exclusion criteria were as follows:

- EDSS score higher than 8

- Karnofsky performance status lower than $70 \%$

- Been exposed to chemotherapy in the past 3 months.

According to the relationship between fingolimod treatment and pulmonary dysfunction, we excluded all the subjects who had previous exposure to fingolimod ${ }^{6}$.
Groups were divided according to the clinical type of MS to analyze the differences in PFTs among the spectrum of the disease. Demographic and clinical variables (body mass index [BMI]), smoking status, age, etc.) were registered to compare them between the aforementioned groups.

\section{Pulmonary function assessment}

PFTs were carried out by trained physicians with Easy on-PC Spirometer (ndd Medizintechnik AG, Zürich, Switzerland). The spirometry was performed to all patients before the HSCT treatment, with the purpose of evaluating the pulmonary function before the administration of the different drugs required and also as a part of the pre-surgical evaluation before the Mahurkar catheter placement. All subjects were recommended to avoid smoking, recent alcohol consumption, or consuming large meals before the test, according to international guidelines ${ }^{7-10}$. The volumes reported in this study included: forced vital capacity (FVC) and forced expiratory volume of the $1^{\text {st }} \mathrm{S}$ (FEV1) in liters (L) and predicted (\%) values and FEV1/FVC ratio. The results of the pulmonary assessment were compared to reference values proposed by the NHANES III reference equations ${ }^{11}$.

\section{Statistical analysis}

All statistical analyses were performed with Prism 7 (GraphPad Software, Inc. La Jolla, CA, USA) and Stata 14 (StataCorp LLC, College Station, TX, USA). For all the analyses, $p<0.05$ was considered statistically significant. The data were assessed for normality with the D'Agostino and Pearson test. Data are expressed in mean and standard deviation for data with normal distribution, while median and interquartile ranges (IQR) were used for data without normal distribution. Pearson correlation coefficients were calculated to assess the association between the PFT parameters and EDSS values. Multiple linear regression was performed to adjust EDSS and respiratory parameters to confounding variables such as age, BMI, smoking status, and length of disease.

\section{Results}

\section{Subjects}

A total of 549 patients with MS were identified, from which, 83 were excluded since they had previous 
Table 1. Demographic data

\begin{tabular}{|l|c|c|c|c|c|}
\hline Variables & Global (n= 466) & RRMS (n= 196) & PPMS (n= 103) & SPMS (n= 167) & $\mathbf{p}$ \\
\hline Male, female & $170 / 296$ & $51 / 145$ & $58 / 45$ & $59 / 108$ & $<0.0001$ \\
\hline Age, mean & 47.6 (SD 9.3) & $44.7(8.8)$ & $49.2(10.8)$ & $50(8)$ & $<0.0001$ \\
\hline Baseline EDSS, median & 6 (IQR 2.5) & $4(3.5)$ & $6(2)$ & $6(1)$ & $<0.0001$ \\
\hline BMI, kg/m & 25.4 (SD 5.3) & $25.4(5.2)$ & $25.1(5.3)$ & $25.8(5.3)$ & 0.6 \\
\hline Ever smokers & $162 / 466$ & $67 / 196$ & $49 / 103$ & $44 / 167$ & 0.02 \\
\hline Length of disease & 11.3 (SD 8.3) & $9.7(8.2)$ & $8(6)$ & $15(8.4)$ & $<0.0001$ \\
\hline Previous DMT & $342 / 466$ & $155 / 196$ & $53 / 103$ & $136 / 167$ & $<0.0001$ \\
\hline
\end{tabular}

BMI: body mass index; EDSS: expanded disability status scale; PPMS: primary progressive multiple sclerosis; RRMS: relapsing remitting multiple sclerosis; SPMS: secondary progressive multiple sclerosis.

Table 2. Pulmonary function assessment results

\begin{tabular}{|c|c|c|c|c|c|}
\hline Variables & Total & PPMS & SPMS & RRMS & $\mathbf{p}$ \\
\hline $\begin{array}{l}\text { Spirometric pattern } \\
\text { Normal } \\
\text { Obstructive } \\
\text { Restrictive }\end{array}$ & $\begin{array}{c}319 / 466 \\
16 / 466 \\
131 / 466\end{array}$ & $\begin{array}{c}62 / 319 \\
5 / 16 \\
36 / 131\end{array}$ & $\begin{array}{l}109 / 319 \\
0 / 16 \\
58 / 131\end{array}$ & $\begin{array}{c}148 / 319 \\
11 / 16 \\
37 / 131\end{array}$ & 0.002 \\
\hline $\begin{array}{l}\text { FVC } \\
\text { FVC, mean (\%) } \\
\text { FVC, mean (L) }\end{array}$ & $\begin{array}{l}88 \text { (SD 17.56) } \\
3.5 \text { (SD 1.02) }\end{array}$ & $\begin{array}{c}86 \text { (SD 16.77) } \\
3.46 \text { (SD 1) }\end{array}$ & $\begin{array}{l}86 \text { (SD 15.24) } \\
3.4 \text { (SD 0.96) }\end{array}$ & $\begin{array}{l}91 \text { (SD 17.54) } \\
3.65 \text { (SD 1.04) }\end{array}$ & $\begin{array}{c}<0.0001 \\
0.53\end{array}$ \\
\hline $\begin{array}{l}\text { FEV1 } \\
\text { FEV1, mean (\%) } \\
\text { FEV1, mean (L) }\end{array}$ & $\begin{array}{c}92 \text { (SD 17.57) } \\
2.94(S D 4.8)\end{array}$ & $\begin{array}{c}\text { 89(SD 17.15) } \\
2.83 \text { (SD 0.83) }\end{array}$ & $\begin{array}{l}\text { 91(SD 15.99) } \\
2.7 \text { (SD 0.77) }\end{array}$ & $\begin{array}{l}93 \text { (SD 17.83) } \\
3.02 \text { (SD 7.40) }\end{array}$ & $\begin{array}{c}0.95 \\
0.3\end{array}$ \\
\hline $\begin{array}{l}\text { FEV1/FVC } \\
\text { FEV1/FVC, mean (\%) } \\
\text { FEV1/FVC, mean (predicted) }\end{array}$ & $\begin{array}{c}82.8 \text { (SD 7.68) } \\
104 \text { (SD 9.77) }\end{array}$ & $\begin{array}{c}83 \text { (SD 7.20) } \\
106 \text { (SD 9.63) }\end{array}$ & $\begin{array}{c}82 \text { (SD 5.69) } \\
104 \text { (SD 7.35) }\end{array}$ & $\begin{array}{l}83.3 \text { (SD 8.09) } \\
103 \text { (SD 10.19) }\end{array}$ & $\begin{array}{c}0.92 \\
0.0016\end{array}$ \\
\hline
\end{tabular}

FEV1: forced expiratory volume of the $1^{\text {st }} \mathrm{s}$; FVC: forced vital capacity; PPMS: primary progressive multiple sclerosis; RRMS: relapsing remitting multiple sclerosis; SD: standard deviation; SPMS: secondary progressive multiple sclerosis.

exposure to fingolimod. The study included 466 patients with relapsing-remitting MS (RRMS) $(n=196)$, primary-progressive MS (PPMS) ( $n=103)$, and secondary-progressive MS (SPMS) $(n=167)$. The median age of the full cohort was 47 (IQR $42-65$ ) being similar among the rest of the groups (Table 1); 296 of individuals were females and 170 males. In the PPMS, the proportion of females and males was almost 1:1, while in the RRMS and SPMS groups, this relation was 2:1 and 3:1, respectively. The registered BMI was similar among all groups: 24.1 RRMS, 24.5 PPMS, and 24.2 SPMS (Table 1). Registered smoking status consisted of 162 ever smokers of all 466 individuals (34\%). The proportion of ever smokers among our population was $162 / 466$, being the PPMS group the one with the highest proportion (50/103).

\section{Pulmonary function assessment}

Of the 466 assessed individuals, 147 (31.7\%) patients were found to have an abnormal pattern of lung function. Of these patients, 131 (89.2\%) and 16 (10.8\%) patients had restrictive and obstructive patterns, respectively (Table 2). The median of predicted FVC was $88 \%$ for the full population, $91 \%$ in the RRMS group, $86 \%$ in the PPMS group, and $86.5 \%$ in the SPMS. The full population had a median FEV1 of $92 \%$, while the RRMS, PPMS, and SPMS groups had $93 \%, 89 \%$, and $91 \%$, respectively. The median FEV1/FVC ratio was $82.8 \%$ in the full cohort, $83.3 \%$ in the RRMS group, $83 \%$ in the PPMS group, and $82 \%$ in the SPMS group (Table 2).

As for the spirometric patterns, $319(68.3 \%)$ patients presented a normal result, $16(3.3 \%)$ an obstructive 
Table 3. Correlation between PFT parameters and clinical disability

\begin{tabular}{|l|c|c|c|c|c|c|c|c|}
\hline Variables & Global & p & RRMS & p & PPMS & p & SPMS & p \\
\hline FVC $(\%)-$ EDSS & -0.39 & $<0.0001$ & -0.40 & $<0.0001$ & -0.31 & 0.0008 & -0.35 & $<0.0001$ \\
\hline FEV1 (\%) - EDSS & -0.32 & $<0.0001$ & -0.27 & $<0.0001$ & -0.28 & 0.0030 & -0.31 & $<0.0001$ \\
\hline FEV1/FVC - EDSS & 0.12 & 0.038 & 0.13 & 0.56 & 0.07 & 0.45 & 0.12 & 0.08 \\
\hline
\end{tabular}

EDSS: expanded disability status scale; FEV1: forced expiratory volume of the $1^{\text {st }}$ s; FVC: forced vital capacity; PPMS: primary progressive multiple sclerosis; RRMS: relapsing remitting multiple sclerosis; SD: standard deviation; SPMS: secondary progressive multiple sclerosis.

pattern, and $131(28.4 \%)$ a restrictive pattern. From the patients who presented a restrictive pattern, $36(27.4 \%)$ had PPMS, 58 (44.2\%) SPMS, and 37 (28.4\%) RRMS.

\section{Correlation of PFTs parameters with clinical disability}

To analyze and find a relation between pulmonary function and the disability caused by MS, Pearson coefficient was calculated, using the EDSS score as the standard parameter for disability measurement and the predicted values of FVC, FEV1, and FEV1/FVC ratio for pulmonary function and severity of restriction. The results showed a weak to moderate inverse correlation between predicted FVC and EDSS score, for the global $(r=-0.39, p \leq 0.0001,95 \%$ confidence interval [Cl] $-0.46--0.32)$, RRMS ( $r=-0.40, p=0.0001,95 \%$ $\mathrm{Cl}-0.51-0.28)$, PPMS $(r=-0.31, p=0.0008,95 \%$ $\mathrm{Cl}-0.48-0.13)$, and SPMS ( $r=-0.35, p \leq 0.0001$, $95 \% \mathrm{Cl}-0.46--0.22$ ) (Table 3). The analysis showed weak to moderate negative correlations between predicted FEV1 and EDSS in the global $(r=-0.32, p \leq 0.0001$, $95 \% \mathrm{Cl}-0.40--0.24)$, RRMS ( $r=0.27, p \leq 0.0001,95 \%$ Cl $-0.39-0.14)$, PPMS $(r=0.28, p \leq 0.003,95 \%$ $\mathrm{Cl}-0.44-0.09)$, and SPMS ( $r=-0.31, p \leq 0.0001$, $95 \% \mathrm{Cl}-0.44-0.18)$. The FEV1/FVC ratio and the EDSS score showed a weak positive correlation among all the groups (Table 3). The adjustment of FVC and FEV1 for EDSS, age, length of disease, BMI, and smoking status showed that, except for EDSS, these variables did not predicted FVC $\left(F[4,461]=19.68, p \leq 0.0001, R^{2}=0.14\right)$ nor FEV1 $\left(F[4,461]=12.23, p \leq 0.0001, R^{2}=0.09\right)$.

\section{Discussion}

Factors contributing to respiratory dysfunction in MS include weakness of the respiratory muscles, bulbar dysfunction, abnormal ventilatory control, and sleep-disordered breathing. Respiratory dysfunction contributes significantly to mortality and morbidity in $\mathrm{MS}^{12}$.
Respiratory complications are one of the most common causes of death in $\mathrm{MS}^{12-16}$. In one large study, respiratory complications accounted for approximately $47 \%$ of all deaths in MS patients ${ }^{17}$. Recognizing which patients with MS are at increased risk for respiratory complications is critical as it may help the clinician to carefully evaluate these patients and initiate appropriate preventive measures. The pathophysiological hallmark of respiratory dysfunction in MS is the presence of demyelinating lesions in the CNS. These lesions may involve one or more locations associated with propagation of neural impulses to the respiratory muscles. Depending on the location and extent of demyelinating lesions, respiratory dysfunction may manifest with symptoms due to respiratory muscle weakness and impaired cough, dysfunction of bulbar muscles, abnormalities in the control of breathing, or respiratory failure. Additional factors such as drugs, disease-related fatigue, or nerve conduction block due to elevated body temperature may independently compromise respiratory muscle function.

Respiratory failure presents in the terminal stages of MS and is usually associated with significant bulbar or limb paralysis ${ }^{18}$. It is uncommon in ambulatory patients. Respiratory failure may be acute, typically secondary to demyelinating lesions in the cervical cord or the medulla, or chronic, typically found in the terminal stages of the disease and related to weak respiratory muscles, and ineffective cough, leading to aspiration, atelectasis, and pneumonia ${ }^{18-20}$. Of the two types, only acute respiratory failure is potentially reversible with treatment ${ }^{19}$.

Acute respiratory failure is a rather uncommon entity. Its clinical characteristics primarily have been described in single cases or small patient series ${ }^{18,19,21-27}$. Patients at risk are those with the relapsing-remitting form of MS and new extensive demyelinating plaques ${ }^{19}$, with acute respiratory failure occurring after a median of 6 years from disease onset. Dyspnea, orthopnea, or confusion often develops over hours or days in patients with no preexisting respiratory dysfunction. Rapid shallow breathing with diminished abdominal excursions or abdominal paradox 
Table 4. Pulmonary function assessment in different international cohorts

\begin{tabular}{|c|c|c|c|c|c|c|}
\hline Reference & $\mathbf{n}$ & Age (SD) & EDSS (range) & FVC $(\%)$ & FEV1 $(\%)$ & FEV1/FVC (\%) \\
\hline Levy et al. ${ }^{10}$ & 73 & 55 (SD 8.7) & $\begin{array}{c}\text { Median } \\
8 \text { (mean } 8.09 \\
\text { SD 0.67) }\end{array}$ & - & 53.6 (SD 28.7) & - \\
\hline Ray et al. ${ }^{11}$ & 37 & 52.7 (SD 10.2) & $\begin{array}{c}3.5 \text { (SD 1.9) } \\
1-6.5\end{array}$ & $\begin{array}{c}3.7 \text { (SD 0.8) } \\
105.2 \text { (SD 18) }\end{array}$ & $\begin{array}{c}2.9 \text { (SD 0.6) } \\
108.3 \\
(S D 20.1)\end{array}$ & 0.80 (SD 0.1) \\
\hline \multirow[t]{2}{*}{ Westerdahl et al. ${ }^{12}$} & 25 (control group) & 56 (SD 9) & $4.5(1.5-8)$ & 3.7 (SD 1.1) & 2.8 (SD 0.7) & 74.8 (SD 6.6) \\
\hline & 23 (interventional group) & 55 (SD 12) & $5.0(3.0-7.0)$ & 3.3 (SD 0.8) & 2.6 (SD 0.7) & 78.4 (SD 7.1) \\
\hline \multirow[t]{2}{*}{ Ray et al. ${ }^{13}$} & 10 (control group) & 56.2 (SD 8.8) & $\begin{array}{c}4.4 \text { (SD 2.1) } \\
1.0-6.0)\end{array}$ & $\begin{array}{c}3.62 \text { (SD 1.05) } \\
103.0 \\
\text { (SD 22.0) }\end{array}$ & $\begin{array}{c}3.07 \text { (SD 0.95) } \\
109.0 \\
\text { (SD 25.0) }\end{array}$ & - \\
\hline & 11 (interventional group) & 50.9 (SD 5.7) & $\begin{array}{c}3.2 \text { (SD 1.9) } \\
1.0-6.5\end{array}$ & $\begin{array}{l}3.39 \text { (SD 0.67) } \\
98.0 \text { (SD 18.0) }\end{array}$ & $\begin{array}{l}2.75 \text { (SD 0.52) } \\
99.0 \text { (SD 17.0) }\end{array}$ & - \\
\hline \multirow[t]{2}{*}{$\begin{array}{l}\text { Bosnak-Guclu, } \\
\text { et al. }^{14}\end{array}$} & $\begin{array}{c}23 \text { (no-minimal } \\
\text { disability) }\end{array}$ & 33.3 (SD 6.31) & $1.0(1.0-2.0)$ & $\begin{array}{c}105.39 \\
\text { (SD 12.16) }\end{array}$ & $\begin{array}{c}98.22 \\
\text { (SD 14.59) }\end{array}$ & $\begin{array}{c}82.14 \\
\text { (SD 8.81) }\end{array}$ \\
\hline & $\begin{array}{l}20 \text { (mild-relatively } \\
\text { severe disability) }\end{array}$ & $\begin{array}{c}38.15 \\
\text { (SD 8.31) }\end{array}$ & $3.5(2.5-4.5)$ & $\begin{array}{c}101.95 \\
\text { (SD 14.17) }\end{array}$ & $\begin{array}{c}97.15 \\
\text { (SD 11.18) }\end{array}$ & $\begin{array}{c}83.51 \\
\text { (SD 6.37) }\end{array}$ \\
\hline Present study & 466 & 47 (SD 9.23) & 6 (SD 1.81) & 88 (SD 17.56) & 92 (SD 17.57) & 82.8 (SD 7.68) \\
\hline
\end{tabular}

EDSS: expanded disability status scale; FEV1: forced expiratory volume of the $1^{\text {st }}$ s; FVC: forced vital capacity; SD: standard deviation.

occurs when there is marked diaphragmatic weakness ${ }^{19}$. FVC is markedly diminished, with values often being $<1 \mathrm{~L}$. A decrement of vital capacity (VC) in the supine position of more than $30 \%$ of that measured in the upright position is indicative of bilateral diaphragm dysfunction ${ }^{28}$ and may be seen in a significant proportion of patients with acute respiratory failure ${ }^{19}$. On magnetic resonance imaging (MRI), individuals often have demyelinating lesions involving the medulla or the spinal cord interfering with motor output to the respiratory muscles. In the series of Howard et al., the majority of patients had quadriplegia, or spastic paraplegia with upper arm weakness, of moderate or severe degree ${ }^{19}$.

The chronic type of respiratory failure usually occurs in the terminal stages of the disease and is associated with significant bulbar dysfunction ${ }^{19}$. Typically, these patients are wheelchair-bound, with upper extremity weakness and weak respiratory muscles ${ }^{19}$. Frequent episodes of aspiration and atelectasis in conjunction with respiratory muscle weakness and a weak cough may lead to bouts of pneumonia and frequent hospitalizations. However, advanced respiratory support with mechanical ventilation and/or permanent tracheostomy is unusual in Pittock et al. described 22 MS patients over 33 years who required mechanical ventilation or tracheostomy $^{25}$. The most common indications for mechanical ventilation or tracheostomy were aspiration pneumonia and mucous plugging and difficulty in removing bronchial secretions ${ }^{25}$. The majority of patients had progressive MS, with a median survival of 22 months following mechanical ventilation ${ }^{25}$.

PFT may provide clues as to whether respiratory muscle dysfunction is present. Lung volumes, such as total lung capacity, VC, and residual volume, may be reduced in patients with severe respiratory muscle weakness. However, the strength of the respiratory muscles must be reduced to as much as $50 \%$ of predicted before any significant reduction in lung volume is measured ${ }^{1}$. Thus, these lung volumes may be normal in patients with mild to moderate respiratory muscle weakness ${ }^{20,28,29}$ and are likely diminished in bedridden patients who have respiratory muscle weakness ${ }^{30}$. FVC is usually within the normal range in ambulatory or ambulatory with assistance (EDSS < 7) MS patients.

In contrast, FVC is moderately decreased in wheelchair-bound and severely decreased in bedridden patients ${ }^{20,31-35}$. Similar changes were also reported for FEV1 and maximal voluntary ventilation (MVV). Besides, FVC does not correlate with the duration of disease $^{31,34}$. In several studies ${ }^{20,30-34,36}$, the FVC and/or MVV correlated with the level of disability as assessed by the EDSS scale. 
Our study found correlations between predicted FVC and FEV1 and EDSS scores among all the groups, similarly to the reports from Pinedo et al., Pittock et al., and Katsenos et al. ${ }^{24,25,27}$ These findings may represent a progressive respiratory dysfunction, even in the RRMS group. However, longitudinal studies about these phenomena may be needed. In comparison with other series from cross-sectional studies and randomized clinical trials (Table 4) our population consisted of older and more affected individuals. However, spirometry parameters remain somewhat similar, which may represent a more advanced stage of respiratory dysfunction but with the same pattern of evolution.

Several studies have been done with the aim of analyzing the relation between spirometric parameters and the severity of MS; nevertheless, these studies used a low sample to find this correlation. In 2017, Levy et al. analyzed 73 patients with severe MS, finding a relation between the severity of the disease and a restrictive pattern on spirometry ${ }^{37}$. In contrast with other studies, our group of 514 patients supports this study as one with the largest population. The patients analyzed in this work included patients with three different types of MS (RRMS, PPMS, and SPMS), giving the study a more significant outlook of how the disease is behaving in the pulmonary function in each type of MS.

Although our study showed congruent and compatible results with previous studies, these have to be interpreted with caution, since simple spirometry was performed as a means to evaluate the respiratory function in this population. As previously used by Ray et al. and Bosnak-Guclu et al., there is a vast number of tests available to assess the complex respiratory changes observed in individuals with MS, which may help to establish a further characterization of respiratory dysfunction in these patients ${ }^{38-41}$. Another limitation accounts for the fact that only EDSS was employed as a measure of clinical and physical disability. The inclusion of additional objective measures, such as MRI outcomes, could provide more in-depth information about the relationship between the respiratory function and the load of brain and spinal cord damage.

\section{Conclusion}

Respiratory dysfunction in individuals with MS has a rather specific pattern of presentation consisting of restriction. This study showed a considerable number of restrictive patterns among all the participants, being the SPMS the type of MS with higher respiratory involvement. The parameters used in simple spirometry had a moderate correlation with the level of disability among all the groups; this could be further analyzed to establish the role of PFTs in the comprehensive evaluation of MS.

\section{Conflicts of interest}

The authors declare that they have no conflicts of interest.

\section{Ethical disclosures}

Protection of human and animal subjects. The authors declare that the procedures followed were in accordance with the regulations of the relevant clinical research ethics committee and with those of the Code of Ethics of the World Medical Association (Declaration of Helsinki).

Confidentiality of data. The authors declare that they have followed the protocols of their work center on the publication of patient data.

Right to privacy and informed consent. The authors have obtained the written informed consent of the patients or subjects mentioned in the article. The corresponding author is in possession of this document.

\section{References}

1. Tzelepis GE, McCool FD. Respiratory dysfunction in multiple sclerosis. Respir Med. 2015;109:671-9.

2. Goldenberg MM. Multiple sclerosis review. P T. 2012;37:175-84

3. Calabresi PA. Diagnosis and management of multiple sclerosis. Am Fam Physician. 2004:70:1935-44.

4. Ruiz-Argüelles GJ, León-Peña AA, León-González M, Nuñez-Cortes AK, Olivares-Gazca JC, Murrieta-Alvarez I, et al. A feasibility study of the full outpatient conduction of hematopoietic transplants in persons with multiple sclerosis employing autologous non-cryopreserved peripheral blood stem cells. Acta Haematol. 2017;137:214-9.

5. Afessa B, Abdulai RM, Kremers WK, Hogan WJ, Litzow MR, Peters SG et al. Risk factors and outcome of pulmonary complications after autologous hematopoietic stem cell transplant. Chest. 2012;141:442-50.

6. Bianco A, Patanella AK, Nociti V, De Fino C, Lucchini M, Savio FL, et al. Severe dyspnoea with alteration of the diffusion capacity of the lung associated with fingolimod treatment. Mult Scler Relat Disord. 2016; 9:11-3.

7. Vosoughi R, Freedman MS. Therapy of MS. Clin Neurol Neurosurg. 2010;112:365-85.

8. Wens I, Eijnde BO, Hansen D. Muscular, cardiac, ventilatory and metabolic dysfunction in patients with multiple sclerosis: implications for screening, clinical care and endurance and resistance exercise therapy, a scoping review. J Neurol Sci. 2016;367:107-21.

9. Miller MR, Crapo R, Hankinson J, Brusasco V, Burgos F, Casaburi R et al. General considerations for lung function testing. Eur Respir J. 2005; 26:153-61.

10. Miller MR, Hankinson J, Brusasco V, Burgos F, Casaburi R, Coates A, et al. Standardisation of spirometry. Eur Respir J. 2005;26:319-38.

11. Culver BH, Graham BL, Coates AL, Wanger J, Berry CE, Clarke PK, et al. Recommendations for a standardized pulmonary function report. An official american thoracic society technical statement. Am J Respir Crit Care Med. 2017;196:1463-72.

12. Sadovnick AD, Eisen K, Ebers GC, Paty DW. Cause of death in patients attending multiple sclerosis clinics. Neurology. 1991:41:1193-6.

13. Koch-Henriksen N, Brønnum-Hansen $\mathrm{H}$, Stenager E. Underlying cause of death in danish patients with multiple sclerosis: results from the danish multiple sclerosis registry. J Neurol Neurosurg Psychiatry. 1998;65:56-9. 


\section{G.J. Ruiz-Delgado, et al: Respiratory impairment in multiple sclerosis}

14. O'Malley F, Dean G, Elian M. Multiple sclerosis and motor neurone disease: survival and how certified after death. J Epidemiol Community Health. 1987;41:14-7.

15. Phadke JG. Survival pattern and cause of death in patients with multiple sclerosis: results from an epidemiological survey in north east scotland. J Neurol Neurosurg Psychiatry. 1987;50:523-31.

16. Ragonese $P$, Aridon $P$, Salemi G, D'Amelio M, Savettieri G. Mortality in multiple sclerosis: a review. Eur J Neurol. 2008;15:123-7.

17. Hirst C, Swingler R, Compston DA, Ben-Shlomo Y, Robertson NP. Survival and cause of death in multiple sclerosis: a prospective population-based study. J Neurol Neurosurg Psychiatry. 2008;79:1016-21.

18. Cooper CB, Trend PS, Wiles CM. Severe diaphragm weakness in multiple sclerosis. Thorax. 1985;40:633-4.

19. Howard RS, Wiles CM, Hirsch NP, Loh L, Spencer GT, Newsom-Davis J. Respiratory involvement in multiple sclerosis. Brain. 1992;115:479-94.

20. Smeltzer SC, Utell MJ, Rudick RA, Herndon RM. Pulmonary function and dysfunction in multiple sclerosis. Arch Neurol. 1988;45:1245-9.

21. Aisen M, Arlt G, Foster S. Diaphragmatic paralysis without bulbar or limb paralysis in multiple sclerosis. Chest. 1990;98:499-501.

22. Balbierz JM, Ellenberg M, Honet JC. Complete hemidiaphragmatic paralysis in a patient with multiple sclerosis. Am J Phys Med Rehabil. 1988;67:161-5

23. Kuwahira I, Kondo $\mathrm{T}$, Ohta $\mathrm{Y}$, Yamabayashi $\mathrm{H}$. Acute respiratory failure in multiple sclerosis. Chest. 1990;97:246-8.

24. Pinedo A, Mateo I, Garcia-Monco JC. Multiple sclerosis and acute weakness of the bulbar and respiratory muscles. Neurologia. 2004;19:213-4.

25. Pittock SJ, Rodriguez M, Wijdicks EF. Rapid weaning from mechanical ventilator in acute cervical cord multiple sclerosis lesion after steroids. Anesth Analg. 2001;93:1550-1.

26. Yamamoto $T$, Imai $T$, Yamasaki M. Acute ventilatory failure in multiple sclerosis. J Neurol Sci. 1989;89:313-24.

27. Katsenos C, Androulaki D, Lyra S, Tsoutsouras T, Mandragos C. A 17 year-old girl with a demyelinating disease requiring mechanical ventilation: a case report. BMC Res Notes. 2013;6:22.

28. McCool FD, Tzelepis GE. Dysfunction of the diaphragm. N Engl J Med. 2012;366:932-42

29. Aiello M, Rampello A, Granella F, Maestrelli M, Tzani P, Immovilli P, et al. Cough efficacy is related to the disability status in patients with multiple sclerosis. Respiration. 2008;76:311-6.
30. Gosselink R, Kovacs L, Ketelaer P, Carton H, Decramer M. Respiratory muscle weakness and respiratory muscle training in severely disabled multiple sclerosis patients. Arch Phys Med Rehabil. 2000;81:747-51.

31. Buyse B, Demedts M, Meekers J, Vandegaer L, Rochette F, Kerkhofs L, et al. Respiratory dysfunction in multiple sclerosis: a prospective analysis of 60 patients. Eur Respir. J 1997;10:139-45.

32. Smeltzer SC, Skurnick JH, Troiano R, Cook SD, Duran W, Lavietes MH et al. Respiratory function in multiple sclerosis. Utility of clinical assessment of respiratory muscle function. Chest. 1992;101:479-84.

33. Tantucci C, Massucci M, Piperno R, Betti L, Grassi V, Sorbini CA, et al. Control of breathing and respiratory muscle strength in patients with multiple sclerosis. Chest. 1994;105:1163-70.

34. Altintas A, Demir T, Ikitimur HD, Yildirim N. Pulmonary function in multiple sclerosis without any respiratory complaints. Clin Neurol Neurosurg. 2007;109:242-6

35. Foglio K, Clini E, Facchetti D, Vitacca M, Marangoni S, Bonomelli M, et al. Respiratory muscle function and exercise capacity in multiple sclerosis. Eur Respir J. 1994;7:23-8.

36. Mutluay FK, Gürses HN, Saip S. Effects of multiple sclerosis on respiratory functions. Clin Rehabil. 2005;19:426-32.

37. Levy J, Bensmail D, Brotier-Chomienne A, Butel S, Joussain C Hugeron C, et al. Respiratory impairment in multiple sclerosis: a study of respiratory function in wheelchair-bound patients. Eur J Neurol. 2017;24: 497-502.

38. Ray AD, Mahoney MC, Fisher NM. Measures of respiratory function correlate with fatigue in ambulatory persons with multiple sclerosis. Disabil Rehabil. 2015;37:2407-12.

39. Bosnak-Guclu M, Gunduz AG, Nazliel B, Irkec C. Comparison of functional exercise capacity, pulmonary function and respiratory muscle strength in patients with multiple sclerosis with different disability levels and healthy controls. J Rehabil Med. 2012;44:80-6.

40. Westerdahl E, Wittrin A, Kånåhols $M$, Gunnarsson M, Nilsagård Y. Deep breathing exercises with positive expiratory pressure in patients with multiple sclerosis a randomized controlled trial. Clin Respir. J 2016;10: 698-706.

41. Ray AD, Udhoji S, Mashtare TL, Fisher NM. A combined inspiratory and expiratory muscle training program improves respiratory muscle strength and fatigue in multiple sclerosis. Arch Phys Med Rehabil. 2013;94: 1964-70. 